\title{
GLOBULOMAXILLARY CYST: DOES IT STILL EXIST? A CASE REPORT
}

\author{
Eleni PANAGOULI ${ }^{1}$, Gregory TSOUCALAS ${ }^{2 凶}{ }^{\circledR}$, Anastasios VASILOPOULOS ${ }^{2}$, \\ Vasilios THOMAIDIS ${ }^{2}$, Aliki FISKA ${ }^{2}$
}

${ }^{1}$ Anatomy Department, Medical School, National and Kapodistrian University of Athens, Athens, Greece

${ }^{2}$ Anatomy Department, Medical School, Democritus University of Thrace, Alexandroupolis, Greece

Received 07 Apr 2019, Accepted 23 May 2019

hitps://doi.org/10.31688/ABMU.2019.54.2.27

\section{Abstract}

Introduction. The globulomaxillary cyst has been under controversy the last few years as an entity of its own. Nevertheless, there are cases of nonodontogenic cysts which cannot be categorized elsewhere.

Case report. We describe such an entity, located in the region of the maxillary lateral incisor and the adjacent canine in a 17-year old patient discovered due to radiology examination. Excision of the mass was performed, a histological examination revealing a cyst lined with ciliated columnar and squamous epithelium followed to confirm the diagnosis of a nonodontogenic cyst.

Conclusions. The scientific debate on the globulomaxillary cyst reveals a controversial or even inappropriate term, but one cannot deny that such kind of oral cysts exists and needs further attention.

Keywords: nasal septum, nonodontogenic cysts, epithelium, canine, incisor.

\section{Résumé}

Le kyste globulomaxillaire, existe-t-il encore? Rapport de cas

Introduction. Le kyste globulomaxillaire a fait l'objet d'une controverse ces dernières années en tant qu'entité distincte. Néanmoins, il existe des cas de kystes nonodontogènes, qui ne peuvent pas être classés ailleurs.

Rapport du cas. Nous décrivons une telle entité, située dans la région de l'incisive latérale maxillaire et de la canine adjacente chez un patient de 17 ans, découverte suite à un examen radiologique. Une excision de la masse a été réalisée. Un examen histologique révélant la présence d'un kyste tapissé d'épithélium cylindrique cilié et squameux a ensuite été confirmé pour affirmer le diagnostic d'un kyste non-odontogène.

Conclusions. Le débat scientifique sur le kyste globulomaxillaire révèle un terme controversé, voire inapproprié, mais il est indéniable que ce type de kystes buccaux existe et nécessite une plus grande attention.

Mots-clés: cloison nasale, kystes non-odontogènes, épithélium, canin, incisive. 


\section{INTRODUCTION}

The last decades, the so-called "globulomaxillary cyst" has been under controversy as an entity of its own. Globulomaxillary cysts are considered to be a type of developmental cysts. The most appropriate definition seems to be a nonodontogenic translucence cyst which develops in the region of the maxillary lateral incisor and the adjacent canine ${ }^{1}$. Globulomaxillary cysts are being evolved in the globular and maxillary process fusion area with an etiology similar to oral and facial clefts, which explains why they are classified as nonodontogenic fissural cysts. However, some clefts are not localized precisely on the premaxillary and maxillary process fusion area and their etiology as globulomaxillary cysts is strongly questioned $^{2}$. Ferenczy, was the first to propose that the point of fusion of the embryonic processes was anterior to and not at the bone suture seen between the maxillary lateral incisor and canine teeth (the globulomaxillary, incisive, or premaxillary-maxillary suture), the suture in which the cyst was believed to form ${ }^{3}$. Intraorally, a globulomaxillary cyst presents as a soft-tissue swelling of the maxillary anterior mucolabial fold, lateral to midline leading to obliteration of the nasolabial fold. The teeth involved seem to preserve full vitality. The cyst in most cases presents the characteristic shape of a reverse pear ${ }^{1,4-5}$.

The first description of this type of cyst was made by Thomas in $1937^{6}$. Since then, several studies propose the elimination of the term as a self-sufficient entity ${ }^{1,7}$. Nevertheless, there are more than a few reports in the literature of true globulomaxillary cysts which cannot be ignored ${ }^{2,8-12}$.

\section{Case report}

We describe a case of a nonodontogenic cyst in a young male, which can, to our knowledge, only be categorized as a globulomaxillary cyst.

The mentioned variation was discovered in a 17 years-old male patient, who presented to the outpatient department. The patient complained of a dislocation of his upper left anterior teeth, observed the last 3 months without pain or other symptoms the preceding months The boy had good growth, the expected weight and stature for his age and no health problems. His past medical, dental, and family history were uneventful. Additionally, his teeth were intact, no toothache and loosening of teeth were mentioned. Clinical examination revealed a small soft spherical swelling at the site of left upper lateral incisor which on palpation was nontender, solitary and immobile. The mass had the same characteristics on intraoral examination as well. The general physical examination and lymph node examination did not reveal any abnormalities. Radiographical examination revealed a well-defined pear-shaped mass of $1.5 \times 2 \mathrm{~cm}$ at the left maxillary region over the upper lateral incisor and canine (Figures 1 and 2). Due to the clinical and anatomical characteristics we assumed that it was probably a globulomaxillary cyst. Excision of the mass was performed (Figures 3 and 4), followed by histological examination which revealed a cyst lined with ciliated columnar and squamous epithelium, which confirmed the diagnosis of a nonodontogenic cyst.

\section{Discussion}

Oral origin masses are classified as those of non-odontogenic (fissural) origin which develop from

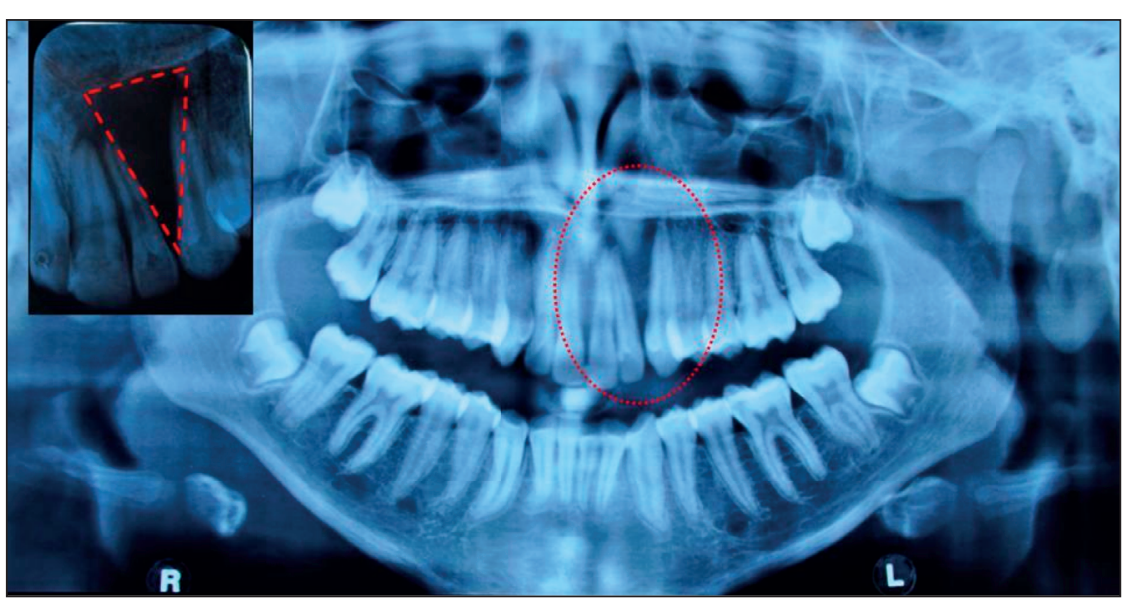

Figure 1. Globulomaxillary cyst showing the characteristic inverted pear-shaped appearance between the maxillary canine and lateral incisor, X-ray (small image). Panoramic X-ray demonstrating the globulomaxillary cyst (large image).

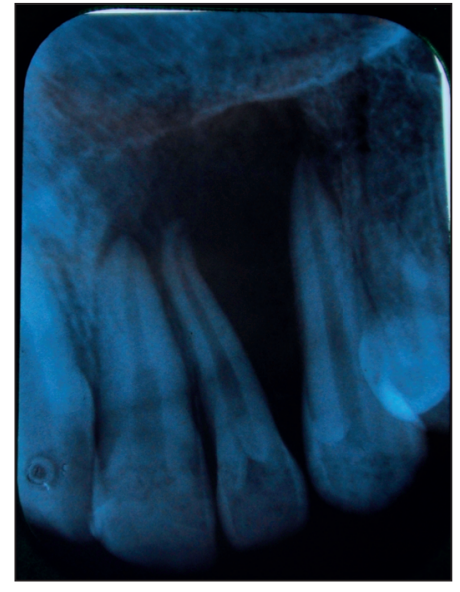

Figure 2. A pear-shaped mass located at the left maxillary region over the upper lateral incisor and canine, local x-ray. 


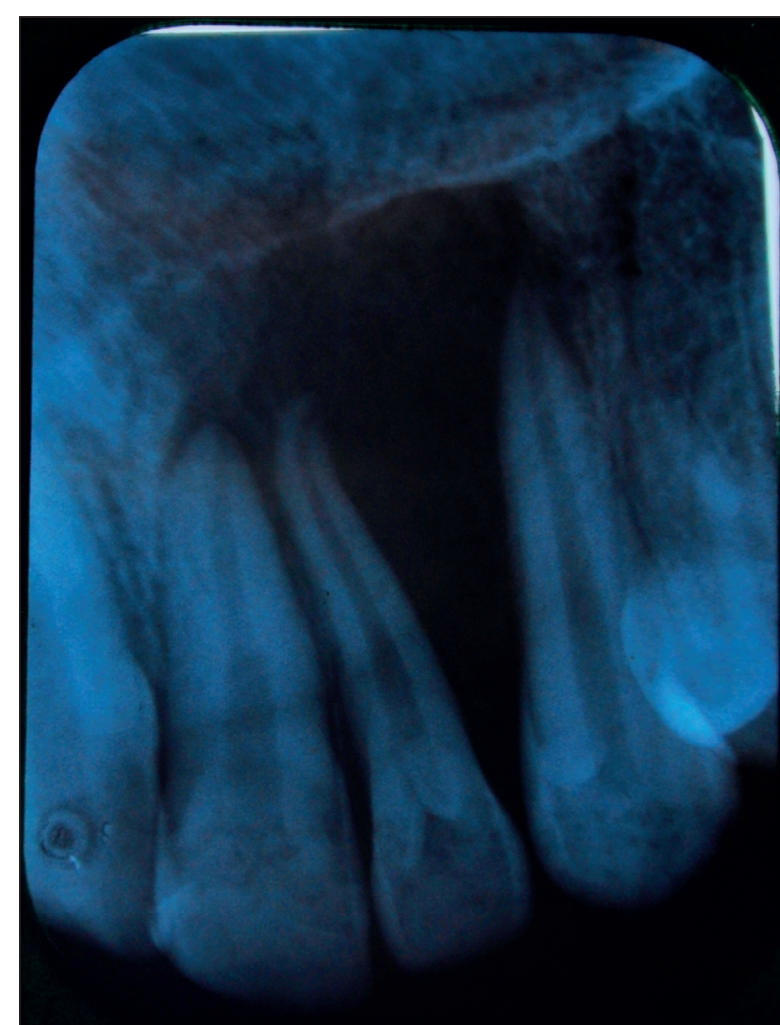

Figure 3. A globulomaxillary cyst located on the left side, surgical excision.

the trapped epithelium because of the fusion of upper jaw bones and those of odontogenic origin which arise from tooth developing epithelium. The first category includes the globulomaxillary, nasopalatine, median palatal and nasolabial (naso alveolar) cysts and the second includes the dentigerous cysts, primordial cysts, odontogenic keratocysts and residual cysts?.

Globulomaxillary cysts are fissural cysts of nonodontogenic origin which are located in the globular and maxillary process fusion area, with an etiopathogenesis similar to that of oral and facial clefts ${ }^{1,4}$. The most likely cause seems to be an epithelial entrapment between the nasal and maxillary process, as they are categorized as nonodontogenic cysts 9 . However, many kinds of tumors might develop in the globulomaxillary area, such as periodontal cysts, radicular cysts and keratocystic or adenomatoid odontogenic tumours ${ }^{1}$. The classic globulomaxillary cyst image in radiology is that of an inverted pear-shaped or tears-shaped, with well-defined radiolucency between the separated roots of lateral incisor and canine ${ }^{13}$. This should be differentiated from the anatomic depression in the labial plate between the maxillary canine and lateral incisor. Due to that fact a careful recording of the case history, a precise clinical examination, adequate imaging and a histopathological

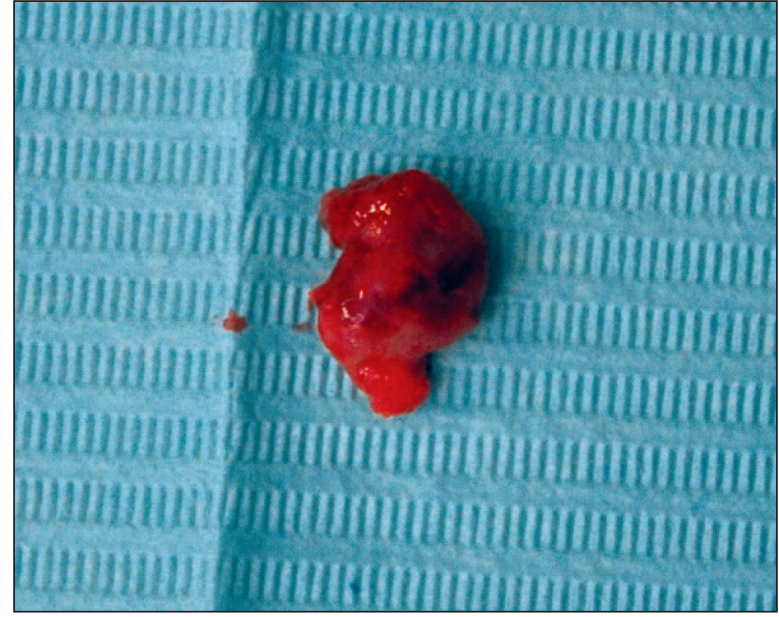

Figure 4. The globulomaxillary cyst after excision.

report are necessary in order to provide the correct diagnosis and the appropriate treatment.

According to the available literature, a mass could be considered as globulomaxillary cyst if it meets the following criteria: (a) Globulomaxillary location and vitality of associated teeth (which are considered as clinical criteria), (b) Shape of a reverse pear and divergence of the roots of the associated teeth (which constitutes the radiographic criteria) and (c) The nature of the lining of the cyst (which is an histologic criterion) $)^{2}$. The mass in our case followed all the above-mentioned criteria, leading to a safe diagnosis. As no other nomenclature can describe such a lesion, we adopt the term "globulomaxillary cyst" in accordance with other similar studies s,8-12 $^{4}$. According to Huston et al in 2017, such a type of cyst presents specific features that cannot match to other potential diagnoses ${ }^{8}$. Häring et al in their study, after a comprehensive analysis of literature, concluded that globulomaxillary cyst does not seem to be an entity of its own and thus it should not be classified as one. They suggest that the term globulomaxillary should be used only in order to define a lesion between the maxillary lateral incisor and the adjacent canine? According to them, the final diagnosis could occur only after a thorough clinical, radiological and histopathological examination ${ }^{1,7}$. A fact that confirms the controversy around the term of globulomaxillary cyst is that it was not published and recognized as an entity at the WHO classification of head and neck tumors of $2005^{1}$. On the other hand, this cannot be an important argument, as Dammer et al (2014) mention in their study, highlighting that odontogenic jaw cysts are not included at all in the 2005 classification. Additionally, the globulomaxillary cyst has been in the WHO classification since 1970 when it was firstly introduced, although it was removed in 


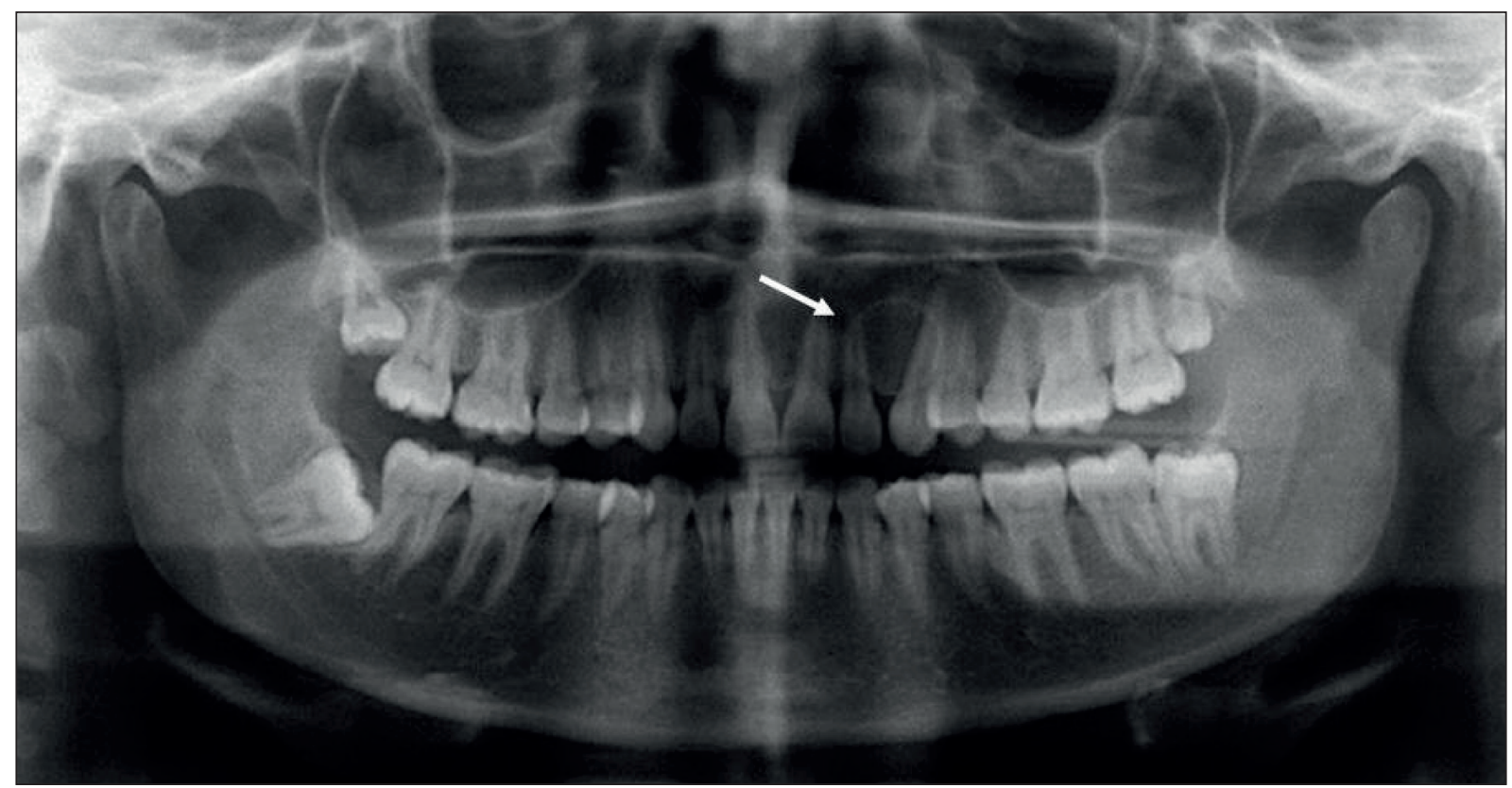

Figure 5. A well-defined, round, unilocular radiolucency

with corticated border in between the displaced roots of 22 and 23, Reddy et al, 2017.

newer editions. However, the term may not be included but the description remains, as a fissural cyst of entrapped epithelium between the globular portion of the medial nasal and maxillary processes ${ }^{10}$. Nevertheless, it remains a "shady" and unspecified entity which needs further research in order to obtain a more descriptive and specific classification.

Globulomaxillary cysts constitute $17 \%$ of all nonodontogenic and nonepithelial cysts of the jaws as reported in earlier studies. However, a meta-analysis demonstrated that many of the original diagnoses were incorrectly announced. A pulpless central incisor, odontogenic keratocysts, adenomatoid odontogenic tumors, radicular cysts, surgical defects, myxomas, anatomic variations, giant cell granulomas, and periapical granulomas may mimic and masquerade a globulomaxillary cyst ${ }^{14-15}$. There is a case report presenting a panoramic radiograph which revealed a unique solitary, well-defined, round, unilocular radiolucency with corticated border overlying the displaced roots of 22 and 23 (Figure 5) ${ }^{16}$. Aisenberg and Inman announced a very rare case of ameloblastoma arising from the epithelium of a nonodontogenic globulomaxillary cyst ${ }^{17}$. Robinson et al noted in a GBC both stratified, squamous, and ciliated columnar epithelium, with clinical, radiographic, and microscopic evidences compatible with a diagnosis of an infected $\mathrm{GBC}^{18}$.

A globulomaxillary cyst might lead to disposition of teeth involved or inflammation. Rarely, a globulomaxillary cyst might enter the nasal cavity ${ }^{9 \cdot 10,19}$ causing nasal obstruction, bleeding, inflammation and cosmetic deformity. Thus, the certain diagnosis and rapid treatment with excision of the cyst are essential ${ }^{1,9}$. The excision can be a simple procedure performed by sub-labial approach, which helps avoiding any cosmetic deformity. It is essential to avoid rapture of the cyst during the surgery, as that could lead to the release of its epithelium cells and the possible recurrence of the mass. Trepanning seems to be an inappropriate method in the cases of globulomaxillary cyst, as it might result to unnecessary injury and lose of vital teeth ${ }^{10}$. As it was mentioned before globulomaxillary cyst is always accompanied by vital teeth. This seems to be another reason why the correct diagnosis in such masses is rather important.

\section{Conclusions}

Globulomaxillary cysts might be a subject of controversy and a dying term; nevertheless, entities as the one observed in our case cannot be categorized in any other type of pathological lesions. Odontogenic and nonodontogenic masses present many similarities as far as their clinical image is concerned. Nevertheless, they require different treatment, thus the knowledge of their histological, topographic and radiologic characteristics is essential for the final diagnosis. This fact combined with that of the term globulomaxillary cyst being disputed highlights the need of a new classification including and describing all the types of these entities. Finally, the nomenclature of the globulomaxillary cyst might be controversial or even inappropriate but no one can denies that such kind of oral cysts exists and needs treatment. 


\section{Compliance with Ethics Requirements:}

„The authors declare no conflict of interest regarding this article"

„The authors declare that all the procedures and experiments of this study respect the ethical standards in the Helsinki Declaration of 1975, as revised in 2008(5), as well as the national law. Informed consent was obtained from the patient included in the study"

"No funding for this study"

\section{References}

1. Dammer U, Driemel O, Mohren W, Giedl C, Reichert TE. Globulomaxillary cysts - do they really exist? Clin Oral Investig. 2014;18(1):239-46.

2. Audion M, Siberchicot F. Globulomaxillary cyst. Rev Stomatol Chir Maxillofac. 2010;111(1):25-26.

3. Ferenczy K. The relationship of globulomaxillary cysts to the fusion of embryonal processes and to cleft palates. Oral Surg. 1958;11(12):1388-1393.

4. Hollinshead MB, Schneider LC. A histologic and embryologic analysis of so-called globulomaxillary cysts. Int J Oral Surg. 1980;9(4):281-286.

5. Bran\& W, Roper-Hall HT. The etiology of cysts of developmental origin in the premaxillary region. Brit D J .1941;70: 213-221.

6. Thoma KH. Facial cleft or fissural cyst. Int J Orthodont. 1937;23:83-89.

7. Haring P, Filippi A, Bornstein MM, Altermatt HJ, Buser D, Lambrecht JT. The "globulomaxillary cyst", a specific entity or a myth? Schweiz Monatsschr Zahnmed. 2006;116:380-397.
8. Huston M, Baker A, Davidson M. Globulomaxillary cyst fact or fiction - a case report. International Journal of Oral and Maxillofacial Surgery. 2017;46(Suppl 1):276.

9. Sharma BB, Sharma S, Jha A, Sharma KD, Sharma JD, Sharma CB. Non-odontogenic hard palate cysts with special reference to globulomaxillary cyst. Plast Aesthet Res. 2016;3:302-305.

10. Arunkumara JS, Prasadb KC, Santhoshc SG, Ahsand M. Globulomaxillary cyst presenting as a nasal mass. Indian Journal of Dentistry. 2012;3(2):86-88.

11. Chimenti C, Monaco A, Nardi E, Volpe F. Globulomaxillary cysts. Minerva Stomatol. 1996;45(12):589-592.

12. D'Silva NJ, Anderson L. Globulomaxillary cyst revisited. Oral Surg Oral Med Oral Pathol. 1993;76:182-184.

13. Saran G, Umapathy D, Mishra N, Channaiah SK, Sumalatha G, Rai P. Globulomaxillary cyst in a 16 year old male patient - a case report with review. Journal of Oral Medicine, Oral Surgery, Oral Pathology and Oral Radiology .2016; 2(3):164-166.

14. Steiner DR. A lesion of endodontic origin misdiagnosed as a globulomaxillary cyst. J Endod. 1999;25(4):277-81.

15. Wood NK, Goaz PW. Textbook of differential diagnosis of oral and maxillofacial lesions, 5th Edition. Mosby, St Louis, 2007.

16. Reddy LS, Jain V, Mittal S, Gupta SD. Full moon shaped unusual appearance of a globulomaxillary cyst: A case report. J Indian Acad Oral Med Radiol. 2017;29(1):50-2.

17. Aisenberg MS, Inman BW. Ameloblastoma arising from a globulomaxillary cyst. Oral Pathology. 1960;13(11):1352-1355.

18. Robinson HBG, Koch WE, Jasper LH. Infected globulomaxillary cyst. American Journal of Orthodontics and Oral Surgery. 1943;29(11):608-611.

19. Yamamoto E, Sato T, Kishimura M, Shimizu M, Ueno T. Globulomaxillary cyst extending to the nasal region-Report of two cases (author's transl). Kokubyo Gakkai Zasshi. $1976 ; 43: 549-554$ 